\title{
Indications and types of hysterectomy in the National Referral Hospital of Bhutan in 2020
}

\author{
Namkha Dorji ${ }^{1}$, Kencho Zangmo ${ }^{2}$, Sangay Tshering ${ }^{3}$, Renuka Mongar ${ }^{4}$, Sonam ${ }^{5}$ \\ ${ }^{1,3}$ Department of Obstetrics \& Gynaecology, Jigme Dorji Wangchuck National Referral Hospital, Thimphu, Bhutan \\ ${ }^{2,4,5}$ Department of Nursing Administration \& Services, Jigme Dorji Wangchuck National Referral Hospital, Thimphu, Bhutan
}

\begin{abstract}
Introduction: Hysterectomy, the removal of uterus, is one of the major gynecological surgeries performed in Bhutan. It is performed for both benign and malignant gynecological conditions. This study was conducted to determine the indications and types of hysterectomies including duration of surgery, and duration of hospital stay after hysterectomy at the National Referral Hospital of Bhutan. Methods: This was a retrospective study conducted at Jigme Dorji Wangchuck National Referral Hospital (JDWNRH) which serves as a National Referral Hospital in Bhutan. Data of women who had hysterectomy from $1^{\text {st }}$ January to $31^{\text {st }}$ December 2020 was extracted into a structured questionnaire from the patient records maintained at the record section in the hospital. Data were entered into Epidata and descriptive statistics were used to analyse using STATA (version IC/14). Results: The mean age of women who had hysterectomy in 2020 was 49 years with age range of 27-74 year. Hysterectomy comprised $9.8 \%$ of gynecologic surgeries in 2020 . The most common route of approach was total abdominal hysterectomy, which comprised $81.7 \%$ of hysterectomies. The primary indications for hysterectomy were cervical intraepithelial neoplasia $(n=34)$ and uterine pathologies $(n=30)$ including fibroid, adenomyosis, endometrial hyperplasia, and abnormal uterine bleeding. Majority of the hysterectomies $(92.9 \%)$ were performed under general anesthesia and $97.4 \%$ were done as elective or planned surgeries. The mean $( \pm \mathrm{SD})$ duration of surgery was shortest for vaginal hysterectomy ( $68.8 \pm 17.6$ minutes) and longest for total laparoscopic hysterectomy $(210 \pm 35.2$ minutes). The duration of hospital stay was shortest for vaginal hysterectomy. Conclusions: Total abdominal hysterectomy was the most common route. However, vaginal hysterectomy had shortest duration of surgery. In addition, those who had undergone vaginal hysterectomy had shorter hospital stay.
\end{abstract}

Keywords: Hysterectomy; Operative time; Perioperative period.

\section{INTRODUCTION}

Hysterectomy, the removal of uterus, is one of the most frequently performed major gynecologic surgeries in the world ${ }^{1-4}$. In the United States, the rate of hysterectomy in 2003 was 5.38 per 1,000 women-years ${ }^{3}$. In India, $9.8 \%$ of rural women and $5.3 \%$ of urban women with insurance had hysterectomy as compared to $7.2 \%$ of rural and $4.0 \%$ of urban women without insurance 5 . The most common route was abdominal hysterectomy $(66.1 \%)$, followed by vaginal $(21.8 \%)$ and laparoscopic routes $(11.8 \%)$ in the USA 3 . Similarly, study from one of the teaching hospitals in India, 74.4\% were abdominal hysterectomy, $17.8 \%$ vaginal hysterectomy, and $6.6 \%$ laparoscopic hysterectomy ${ }^{4}$. The common nonmalignant indications for hysterectomy are symptomatic uterine fibroids, abnormal uterine bleeding, endometriosis, and prolapsed female reproductive organs ${ }^{6}$. Cervical cancer, ovarian cancer, and uterine cancer are malignant conditions for which hysterectomy

\footnotetext{
Corresponding author:

Namkha Dorji

namji2002@gmail.com
}

is indicated. Postpartum hemorrhage and ruptured uterus are indications for an emergency hysterectomy ${ }^{7}$. Retrograde hysterectomy is performed when there is a dense adhesion present around the uterus; when the cervicovaginal junction is not clearly felt by palpation in condition like uterine rupture after vaginal delivery; and when large mass is present in the vagina ${ }^{8}$.

There is no universal agreement on what proportion of hysterectomies should be performed via each route. The choice of route of hysterectomy should be based on individual patient profile, the expertise of a surgeon and availability of equipment. The individual patient profile for a selection of route of hysterectomy for benign disease would depend on the size and shape of the vagina and uterus; access to the uterus; extent of extrauterine disease; and the need for concurrent procedures ${ }^{6}$. However, the vaginal hysterectomy is considered as the procedure of choice if it is feasible because the vaginal route is associated with less morbidity as compared with other routes ${ }^{9}$. Transvaginal approach hysterectomy was found to be the most cost-effective and associated with shorter hospitalization and faster recovery ${ }^{1}$.

In Bhutan, the socio-demographic profiles, indications, duration of surgery, duration of hospital stay among patients undergoing hysterectomy are unknown despite the increasing 
numbers of hysterectomies performed every year in the country. Thus, this study was conducted to determine the indications and types of hysterectomies including duration of surgery, and duration of hospital stay after hysterectomy at the National Referral Hospital of Bhutan.

\section{METHODS}

After obtaining ethical clearance from the Research Ethics Board of Health, (letter No.REBH/Approval/2020/x03 dated 12/01/2021), a descriptive study was conducted at JDWNRH. JDWNRH as a tertiary care and teaching hospital that not only caters to the population in its locality with basic to complex care facilities but serves as a national referral centre for cases referred from other health facilities across the country.

This descriptive study used information of women who underwent hysterectomy between $1^{\text {st }}$ January to $31^{\text {st }}$ December 2020 at JDWNRH through a census sampling, resulting into a sample size of 115 . The confidentiality of study participants was maintained by removing all personal identifiers, and the data will be preserved for five years.

Data were collected from both hard copy and electronic patient record into a data collection form which included all the study variables. Data were double entered into EpiData file and validated. The study variables included sociodemographic profiles, indications, duration of surgery, duration of hospital stay. Data were cleaned, coded, and analyzed using STATA version IC/14. Descriptive statistics such as frequency, percentage, mean, and standard deviations were used.

\section{RESULTS}

This is a retrospective study conducted among women who underwent hysterectomy at JDWNRH in 2020. During the study period, 1170 gynecologic surgeries were performed including $115(9.8 \%)$ hysterectomies. The mean age of patients in the sample was 49 years with average of 27-74 years. The mean age at which women were married for the first time was 21 with a range of 14-35 years and the mean age at first childbirth was 26 with a range of 15-40 years. Sixty seven (58.2\%) of the patients were housewives $93.9 \%$ were married, and majority were from outside Thimphu (Table 1).

In our study, $81.7 \%$ underwent a total abdominal hysterectomy (TAH), $8.7 \%$ radical hysterectomy, $4.4 \%$ vaginal hysterectomy, and $2.6 \%$ each of total laparoscopic hysterectomy and subtotal hysterectomy. Elective procedures constituted $97.4 \%$ of all the hysterectomies performed, and $92.9 \%$ were done under general anesthesia. The primary indication for TAH were CIN 2+ and uterine pathologies including fibroid, adenomyosis, endometrial hyperplasia and abnormal uterine bleeding (Table 2).

The mean duration of surgery from skin incision to closure was $98.4( \pm 32.9)$ minutes and mean duration of hospital stay was $5.7( \pm 3.3)$ days. Among the hysterectomies, vaginal hysterectomy had the shortest mean duration of surgery $(68.8$ \pm 17.6 minutes) and duration of hospital stay ( $3.6 \pm 0.8$ days). In contrast, total laparoscopic hysterectomy had the longest mean duration of surgery $(210 \pm 35.2$ hours $)$ and subtotal hysterectomy had the longest mean duration of hospital stay $(8$ \pm 4.2 days). Furthermore, among this study sample, $2.6 \%$ had

Table 1. Distribution by sociodemographic characteristics of women who underwent hysterectomy at JDWNRH ${ }^{*}$ in $2020(n=115)$

\begin{tabular}{lll}
\hline Characteristics & $\boldsymbol{n ( \% )}$ & $\mathbf{M}^{\dagger}$ (SD) \\
\hline Age & & $48.8(10.86)$
\end{tabular}

27 to 44 years

$47(40.9)$

45 to 54 years

$35(30.4)$

55 years and above

$33(28.7)$

Occupation

Housewife

$67(58.2)$

Farmer

Civil servant

Businesswoman

Others (Dependent, Anim)

$4(3.5)$

\section{Marital status}

Married

Others (unmarried, widow) 7 (6.1)

\section{Residence area}

Thimphu

Districts other than Thim-

$72(62.6)$ phu

\section{Level of education}

$\begin{array}{ll}\text { Illiterate } & 88(76.5) \\ \text { Literate } & 27(23.5)\end{array}$

Parity

Para 0

Para 1

Para 2

Para 3

More than para 4

Age at first marriage

Minimum $=14$, Maximum $=$ $35, \mathrm{M}\left(\mathrm{SD}^{*}\right)=21.3(11.3)$

Age at first childbirth $\quad$ Minimum $=15$, Maximum $=$ $40, \mathrm{M}\left(\mathrm{SD}^{\prime}\right)=26.4(19.2)$

\footnotetext{
"Jigme Dorji Wangchuck National Referral Hospital

Mean

* Standard deviation

${ }^{\S}$ Pregnancies that have crossed 28 weeks of gestation
} 
TLH. It took long time to complete the surgery, whereby one case had to be converted to TAH due to malfunction of equipment intraoperatively (Table 3).

Table 2. Indications and types of hysterectomies at JDWNRH* in $2020(n=115)$

\begin{tabular}{|c|c|c|c|c|c|}
\hline Types of hysterectomy & $\begin{array}{l}\text { TAH } \\
n(\%)\end{array}$ & $\begin{array}{l}\text { RH } \\
n(\%)\end{array}$ & $\begin{array}{l}\mathrm{VH} \\
n(\%)\end{array}$ & $\begin{array}{l}\text { TLH" } \\
n(\%)\end{array}$ & $\begin{array}{l}\text { STH } \\
n(\%)\end{array}$ \\
\hline \multicolumn{6}{|l|}{$\begin{array}{l}\text { Indications of hysterec- } \\
\text { tomy }\end{array}$} \\
\hline $\begin{array}{l}\text { Cervical intraepithelial } \\
\text { neoplasia }\end{array}$ & $29(85.3)$ & $2(5.9)$ & 0 & $3(8.8)$ & 0 \\
\hline Cervical cancer & $11(57.9)$ & $8(42.1)$ & 0 & 0 & 0 \\
\hline Uterine pathology & $28(93.3)$ & 0 & 0 & 0 & $2(6.7)$ \\
\hline Benign ovarian tumor & $10(100)$ & 0 & 0 & 0 & 0 \\
\hline Malignant ovarian tumor & $9(90.0)$ & 0 & 0 & 0 & $1(10.0)$ \\
\hline Utero-vaginal prolapsed & 0 & 0 & $5(100)$ & 0 & 0 \\
\hline Others & $7(100)$ & 0 & 0 & 0 & 0 \\
\hline Total & $94(81.7)$ & $10(8.7)$ & $5(4.4)$ & $3(2.6)$ & $3(2.6)$ \\
\hline
\end{tabular}

*Jigme Dorji Wangchuck National Referral Hospital

Total abdominal hysterectomy

*Radical hysterectomy

$\S$ Vaginal hysterectomy

"Total laparoscopic hysterectomy

"Subtotal hysterectomy,

Table 3. Comparison of types of hysterectomies, duration of surgery and hospital stay in women who underwent hysterectomy at JDWNRH ${ }^{*}$ in $2020(n=115)$

\begin{tabular}{|c|c|c|c|c|c|c|}
\hline \multirow[t]{2}{*}{$\begin{array}{l}\text { Types of } \\
\text { surgery }\end{array}$} & \multicolumn{3}{|c|}{$\begin{array}{l}\text { Duration of surgery } \\
\text { (minutes) }\end{array}$} & \multicolumn{3}{|c|}{$\begin{array}{l}\text { Duration of hospital } \\
\text { stay (days) }\end{array}$} \\
\hline & Min & Max & $\begin{array}{l}\text { Mean } \\
\left(\mathrm{SD}^{\dagger}\right)\end{array}$ & Min & Max & $\begin{array}{l}\text { Mean } \\
\left(\mathrm{SD}^{\dagger}\right)\end{array}$ \\
\hline $\mathrm{TAH}^{*}$ & 54 & 174 & $94.8(26.3)$ & 4 & 23 & $5.7(3.4)$ \\
\hline $\mathrm{RH}^{\S}$ & 67 & 155 & $109.2(24.1)$ & 4 & 11 & $6.9(2.4)$ \\
\hline $\mathrm{VH}^{\|}$ & 49 & 100 & $68.8(17.6)$ & 2 & 4 & $3.6(0.8)$ \\
\hline $\mathrm{TLH}^{\star}$ & 150 & 240 & $210(35.2)$ & 4 & 4 & $4.0(0.0)$ \\
\hline $\mathrm{STH}^{* *}$ & 91 & 123 & $111.3(14.4)$ & 4 & 14 & $8.0(4.2)$ \\
\hline Overall & \multicolumn{3}{|c|}{$\mathrm{M}^{\dagger}\left(\mathrm{SD}^{+}\right)=98.4(32.9)$} & \multicolumn{3}{|c|}{$\mathrm{M}\left(\mathrm{SD}^{\star}\right)=5.7(3.3)$} \\
\hline
\end{tabular}

"Jigme Dorji Wangchuck National Referral Hospital

'Standard deviation

\$otal abdominal hysterectomy

${ }^{\S}$ Radical hysterectomy, "Vaginal hysterectomy; "Total

laparoscopic hysterectomy; ${ }^{* *}$ Subtotal hysterectomy; "Hean;

*Standard deviation; Min-Minimum; Max-Maximum

\section{DISCUSSION}

The approach for hysterectomy depends on the expertise of the surgeon, availability of equipment, indications, patient characteristics, and informed choices of patients; thus, the type and approach for hysterectomy needs to be individualized. In 2020 , hysterectomy comprised $9.8 \%$ of gynecologic surgeries at JDWNRH and majority of them were abdominal hysterectomies performed under general anesthesia.

Total abdominal hysterectomy being the most common type of hysterectomy in our setting is similar to findings reported elsewhere in other studies ${ }^{3,4,10-12}$. However, only $4.4 \%$ of the sample had undergone vaginal hysterectomy $(\mathrm{VH})$ despite many studies and other standard guidelines recommending vaginal hysterectomy as the safest route with minimal complications and lowest financial implications including early return to normal life $1,6,9,13,14$. Although VH was performed in older women as compared to TAH, the duration of hospital stay was shortest which is comparable to other studies ${ }^{1,9,13,14}$. The shorter hospital stay could be due to lack of abdominal incision scar and surgery being performed under spinal anesthesia, allowing for early ambulation and early return of gastrointestinal function. The reasons for lower rate of $\mathrm{VH}$ despite its numerous benefits both to the patient and health system could be because of lack of expertise to perform non-decent vaginal hysterectomy. In addition, many women with utero-vaginal prolapse prefer ring pessary over $\mathrm{VH}$, out of concern of surgery complications. Interestingly, vaginal route of hysterectomy performed for benign disease was more common than the abdominal route in Germany. They perform $\mathrm{VH}$ for cervical carcinoma in situ and endometrial adenomatous hyperplasia $^{15}$. Other literature on hysterectomy reports that, $\mathrm{VH}$ remains underutilized despite the proven safety and effectiveness of $\mathrm{VH}$ for surgical treatment of non-prolapse conditions ${ }^{16}$.

Subtotal hysterectomy (STH) was done in $2.6 \%$ of the sample, which is $50 \%$ lower than the rates reported from a study in Germany ${ }^{15}$. This could be because, in our setting STH is not practiced routinely except in cases of emergencies to shorten the duration of surgery or in cases where removal of cervix is difficult due to dense adhesions. According to a study from Germany, the relative frequency of STH was dependent on route of approach and about $62 \%$ of laparoscopic hysterectomies resulted in $\mathrm{STH}^{15}$.

Vaginal route is preferred choice if feasible as it is associated with low effective, less morbidity, lower rate of conversion to laparotomy, lower rate of vaginal cuff dehiscence, shorter operative time and shorter perioperative hospital stay ${ }^{9,17}$. Our study showed shorter operative duration and hospital stay though the older women had undergone vaginal hysterectomy. However, defining the best surgical approach is a dynamic process 
that would need frequent re-evaluation with the improvement in technology ${ }^{17}$. To the best of our knowledge, this is the first study on hysterectomy in Bhutan which provides baseline data so that in depth studies in future can be planned.

\section{LIMITATIONS}

The study design being a retrospective study, is the major limitation. Clinical parameters such as presenting complaints, intraoperative complications and postoperative complications of hysterectomy, and histopathology results are not included in this study.

\section{CONCLUSIONS}

From this study, we conclude that the total abdominal hysterectomy was the most common route. However, vaginal hysterectomy had shortest duration of surgery. In addition, those who had undergone vaginal hysterectomy had shorter hospital stay.

\section{RECOMMENDATIONS}

With the insight gained from this study on hysterectomy surgeries, there is need to consider making standard equipment for laparoscopic gynaecologic surgeries available in our setting. In addition, more studies could be done in the context of Bhutan on the safety and cost of different routes of hysterectomies; especially for the nation to sustain its free healthcare services in the long run. It would be interesting to study the cost effectiveness and patient outcomes for different approaches of hysterectomies, and a comparative study between spinal and general anesthesia for hysterectomies.

\section{REFERENCES}

1. Kala E, Stojko R, Sadlocha M. Hysterectomy costs depending on operational technique. Ginekol Pol. 2018;89(12):672-6. [PubMed | Full Text | DOI]

2. Barker MA. Current Issues with Hysterectomy. Obstet Gynecol Clin North Am [Internet]. 2016;43(3):591-601. [Full Text | DOI]

3. Wu JM, Wechter ME, Geller EJ, Nguyen TV, Visco AG. Hysterectomy rates in the United States, 2003. Obstet Gynecol. 2007;110(5):1091-5. [Full Text | DOI]
4. Pandey D, Sehgal K, Saxena A, Hebbar S, Nambiar J, Bhat RG. An Audit of Indications, Complications, and Justification of Hysterectomies at a Teaching Hospital in India. Int J Reprod Med. 2014;2014:1-6. [Full Text | DOI]

5. Desai S, Sinha T, Mahal A. Prevalence of hysterectomy among rural and urban women with and without health insurance in Gujarat, India. Reprod Health Matters [Internet]. 2011;19(37):42-51. [Full Text | DOI]

6. Butts SF. C ommittee opinion. 2017;129(701):155-9.

7. Guylaine Lefebvre, Catherine Allaire, John Jeffrey GV. CLINICAL. J Obs Gynaecol Can 2002;24( I)37-48. 2002;24(1):37-48.

8. Hiramatsu Y. Retrograde Abdominal Hysterectomy. Surg J. 2019;05(S 01):S27-32.

9. Aarts JWM, Nieboer TE, Johnson N, Tavender E, Garry R, Mol BWJ, et al. Surgical approach to hysterectomy for benign gynaecological disease. Cochrane Database Syst Rev. 2015;2015(8). [PubMed | Full Text | DOI]

10. Pandey MR, Ghosh A, Chaulagain P, Kandel K. Clinical profile of patients undergoing abdominal hysterectomy at a medical college in Nepal. 2021;12(2):6-10. [Full Text |DOI]

11. Sharma C, Sharma M, Raina R, Chander B, Soni A, Verma S. Gynecological diseases in rural India: A critical appraisal of indications and route of surgery along with histopathology correlation of 922 women undergoing major gynecological surgery. J Midlife Health. 2014;5(2):55. [PubMed | Full Text | DOI]

12. Butt JL, Jeffery ST, Van Der Spuy ZM. An audit of indications and complications associated with elective hysterectomy at a public service hospital in South Africa. Int J Gynecol Obstet [Internet]. 2012;116(2):112-6. [Full Text | DOI]

13. Garry R, Fountain J, Brown J, Manca A, Mason S, Sculpher M, et al. Evaluate hysterectomy trial: A multicentre randomised trial comparing abdominal, vaginal and laparoscopic methods of hysterectomy. Health Technol Assess (Rockv). 2004;8(26). [PubMed | Full Text | DOI]

14. Lee SH, Oh SR, Cho YJ, Han M, Park J, Kim SJ, et al. Comparison of vaginal hysterectomy and laparoscopic hysterectomy : a systematic review and meta-analysis. 2019. [PubMed | Full Text | DOI] 
15. Stang A, Merrill RM, Kuss O. Hysterectomy in Germany: a DRG-based nationwide analysis, 2005-2006. Dtsch Arztebl Int. 2011 Jul;108(30):508-14. [PubMed | Full Text | DOI]

16. Moen MD, Richter HE. Vaginal hysterectomy: Past, present, and future. Int Urogynecol J Pelvic Floor Dysfunct. 2014;25(9):1161-5. [PubMed | Full Text | DOI]
17. Sandberg EM, Twijnstra ARH, Driessen SRC, Jansen FW. Total Laparoscopic Hysterectomy Versus Vaginal Hysterectomy: A Systematic Review and Meta-Analysis. J Minim Invasive Gynecol [Internet]. 2017;24(2):206-217. e22. [PubMed | Full Text | DOI]

\section{AUTHORS CONTRIBUTION}

Following authors have made substantial contributions to the manuscript as under:

ND: Concept, design, data collection and analysis, manuscript writing and review.

KZ: Data collection and analysis, manuscript writing and review

ST: Data collection and analysis, manuscript writing and review

RM: Data collection and analysis

S: Data collection and analysis, manuscript review

Author agree to be accountable for all respects of the work in ensuring that questions related to the accuracy and integrity of any part of the work are appropriately investigated and resolved.

CONFLICT OF INTEREST

None

GRANT SUPPORT AND FINANCIAL DISCLOSURE

None 